\title{
CARACTERIZAÇÃO TECNOLÓGICA EM AMOSTRAS MINERALIZADAS A ESTANHO DO ESTADO DE RONDÔNIA
}

\author{
A. B. BRAZ, H. KAHN, R. CONTESSOTTO, C. ULSEN E M. M. M. L. TASSINARI \\ Universidade de São Paulo, Escola Politécnica. Depto de Eng. de Minas e de Petróleo. \\ E-mail: henrique@Ict.poli.usp.br
}

Artigo submetido em novembro/2013 e aceito em julho/2014

DOI: http://dx.doi.org/10.15628/holos.2014.1793

\section{RESUMO}

A crescente demanda por estanho no cenário mundial vem promovendo maior interesse no estudo de mineralizações primárias e mais complexas. Nesse contexto, estudos de caracterização tecnológica foram efetuados em duas amostras (sulfetada e oxidada), provenientes do norte do Brasil, Estado de Rondônia, com o objetivo de verificar as características da cassiterita e dos sulfetos presentes e suas associações com a ganga. Os estudos envolveram análises granulométricas, separações minerais e estudos de mineralogia quantitativa por microscopia eletrônica de varredura (MEV/EDS) utilizando análise de imagens automatizada (Mineral Liberation Analyser - MLA), possibilitando a obtenção da composição mineral, as características de associação e de liberação dos minerais de interesse e a partição dos elementos químicos nos minerais portadores. Os resultados indicam que as amostras têm teores semelhantes de estanho e de zinco e a mesma assembleia mineralógica, variando apenas a proporção relativa entre os minerais presentes. O grau de liberação da cassiterita para o material cominuído abaixo de 3,36 mm é da ordem de 40 a $50 \%$. Os estudos sugerem que o processamento da cassiterita poderia ser efetuado em duas etapas de cominuição conjugados com concentração gravítica; os mistos e rejeitos, a depender dos teores de $\mathrm{Sn}$ e Zn, poderiam ser remoídos para a recuperação da esfalerita por flotação, obtendose ainda um eventual concentrado acabado de estanho.

PALAVRAS-CHAVE: cassiterita; caracterização tecnológica; análise de imagens automatizada.

\section{TECHNOLOGICAL CHARACTERIZATION OF TIN ORE SAMPLES FROM RONDÔNIA STATE, BRAZIL}

\begin{abstract}
The growing demand for tin has encouraged studies of primary deposits and more complex ores. This article shows the results of mineralogical and technological characterization carried out in two samples of tin ores (sulfide and oxidized ore) from Rondônia state, Brazil, aiming the to quantify the cassiterite and other sulfides associations with gangue minerals. The studies comprised sieve analysis, mineral separation and quantitative mineralogical studies by scanning electron microscope (SEM/EDS) coupled to automated image analyses (Mineral Liberation Analyser - MLA) for obtaining the mineral composition, association and
\end{abstract}

liberation of minerals of interest and partition of elements in the bearing minerals. The results show that both samples have similar mineralogical composition but differ in proportions; the grades of tin and zinc are also comparable.. The liberation degree of cassiterite for the material crushed below $3,36 \mathrm{~mm}$ is about 40 to $50 \%$. The studies indicate that the tin processing could be carried out in two stages of comminution combined to gravity concentration; the middlings and gravity tailings, depending on their $\mathrm{Sn}$ and $\mathrm{Zn}$ contents, should be regrinding for sphalerite flotation, obtaining any further tin

concentrated.

KEYWORDS: cassiterite; technological characterization; SEM-based quantitative mineralogy 


\section{INTRODUÇÃO}

A descoberta de depósitos de cassiterita em Rondônia, no final da década de 80, juntamente com a jazida de Pitinga (AM), levou o Brasil à condição de maior produtor mundial de estanho entre 1988 e 1990. Na década seguinte, no entanto, com o esgotamento dos depósitos de alto teor, essa posição foi perdida para a China que atualmente lidera a produção mundial.

A crescente demanda de estanho e tendência de preços crescentes tem promovido o interesse na avaliação da potencialidade de mineralizações primárias e mais complexas do ponto de vista de extração e beneficiamento, para as quais são necessários estudos detalhados de caracterização tecnológica.

Neste contexto, este trabalho apresenta os resultados de estudos de caracterização tecnológica efetuados em duas amostras provenientes de mineralizações primárias de Rondônia, tendo por objetivo verificar a forma de ocorrência da cassiterita e sulfetos presentes e suas associações com a ganga contida, bem como a partição do estanho e zinco dentre os minerais portadores, a composição mineralógica das amostras por fração granulométrica, de modo a obter subsídios para posterior desenvolvimento de alternativas de processo visando o seu aproveitamento.

Os estudos envolveram a realização de análises granulométricas e separações minerais, aliadas a análises mineralógicas por microscopia eletrônica de varredura (MEV), microanálises químicas por EDS, difratometria de raios $X$ e análise de imagens automatizada por feixe de elétrons em sistema MLA (Mineral Liberation Analyser - MLA) acoplado a microscópio eletrônico de varredura. A análise de imagens ao MEV-MLA permitiu determinar, para cada amostra, a composição mineralógica e química, a distribuição dos elementos nas fases portadoras, a liberação da cassiterita e o tamanho dos grãos de cassiterita e de esfalerita.

Sistemas de análise de imagens automatizados, além das características mencionadas acima, permitem também a obtenção de informações bem mais consistentes e acuradas que aquelas apresentadas por técnicas tradicionais de estereologia (PETRUK, W, 1989; KAHN et al, 1996; KRAMER et al, 1994; LASTRA et al, 1997; FANDRICH et al, 2007).

\section{MATERIAIS E MÉTODOS}

As amostras denominadas oxidada e sulfetada, oriundas das amostragens de superfície do depósito, foram submetidas ao procedimento experimental descrito a seguir:

Cominuição do material abaixo de 3,36 mm em britador de mandíbulas e de rolos.

Análise granulométrica por peneiramento a úmido em peneiras de aberturas nominais de 2,80 mm, 2,50 mm, 2,36 mm, 1,68 mm, 1,19 mm, 0,84 mm, 0,60 mm, 0,42 mm, 0,30 mm, 0,21 $\mathrm{mm}, 0,15 \mathrm{~mm}, 0,074 \mathrm{~mm}$ e $0,044 \mathrm{~mm}$.

Separações minerais em escala de bancada, utilizando líquidos densos, TBE e di-iodeto de metileno, com densidades de $2,95 \mathrm{~g} / \mathrm{cm}^{3}$ e $3,30 \mathrm{~g} / \mathrm{cm}^{3}$, respectivamente, nas frações de granulação superiores a $0,074 \mathrm{~mm}$. 
Análises químicas de todos os produtos obtidos com determinações de Sn, Zn, SiO2, $\mathrm{Al} 2 \mathrm{O} 3, \mathrm{Fe} 2 \mathrm{O} 3, \mathrm{~K} 2 \mathrm{O}, \mathrm{CaO}, \mathrm{TiO} 2$ e $\mathrm{Cu}$, através de espectrometria de fluorescência de raios $\mathrm{X}(\mathrm{FRX}) \mathrm{e}$ determinação de perda ao fogo a $1.050^{\circ} \mathrm{C}$.

Caracterização mineralógica por MEV-MLA, realizada para as frações do intervalo 0,84+0,074 $\mathrm{mm}$; nas frações acima de $0,84 \mathrm{~mm}$ esses estudos foram efetuados nos produtos afundados obtidos nas separações minerais de modo a se ter maior representatividade estatística para os minerais de interesse.

\section{RESULTADOS E DISCUSSÕES}

\subsection{Composição química}

A composição química das amostras estudadas é apresentada na tabela 1.

Tabela 1 - Composição química das amostras estudadas (análises quantitativas por FRX).

\begin{tabular}{|c|ccccccccc|}
\hline \multirow{2}{*}{ AMOSTRA } & \multicolumn{8}{|c}{ Teores (\% massa) } & \\
& $\mathrm{Sn}$ & $\mathbf{Z n}$ & $\mathbf{S i O}_{\mathbf{2}}$ & $\mathbf{A l}_{\mathbf{2}} \mathbf{O}_{\mathbf{3}}$ & $\mathbf{F e}_{\mathbf{2}} \mathbf{O}_{\mathbf{3}}$ & $\mathbf{K}_{\mathbf{2}} \mathbf{O}$ & $\mathbf{C a O}$ & $\mathbf{P F}$ \\
\hline SULFETADA & 0,55 & 0,29 & 62,3 & 14,8 & 5,04 & 3,89 & 2,00 & 2,72 \\
OXIDADA & 0,55 & 0,28 & 84,9 & 6,18 & 2,81 & 2,57 & 0,25 & 0,50 \\
\hline
\end{tabular}

Ambas as amostras apresentam teores semelhantes de estanho e de zinco, 0,55\% e 0,28$0,29 \%$, respectivamente. A amostra oxidada tem teor mais elevado de $\mathrm{SiO} 2$ do que a sulfetada (84,9\% contra $62,3 \%)$ e menores de $\mathrm{Al} 2 \mathrm{O} 3$ (6,18\% e $14,8 \%$, respectivamente), Fe2O3 (2,81\% e $5,04 \%$, respectivamente), $\mathrm{K} 2 \mathrm{O}(2,57 \%$ contra $3,89 \%)$ e $\mathrm{CaO}(0,25 \%$ contra $2,00 \%)$.

3.2 Distribuição em massa e teores por fração granulométrica após cominuição a $3,36 \mathrm{~mm}$

O sumário dos resultados das distribuições granulométricas, teores e distribuições de Sn e Zn, por fração granulométrica são apresentados na tabela 2 .

A cominuição efetuada a $-3,36 \mathrm{~mm}$ gerou, para as duas amostras, produtos com distribuições granulométricas semelhantes até $0,21 \mathrm{~mm}$; abaixo dessa fração as diferenças se tornam mais significativas, sendo que a amostra sulfetada apresenta quase que o dobro de material passante em $0,074 \mathrm{~mm}$, do que a oxidada, respectivamente, $6,7 \%$ em massa e $3,6 \%$.

$\mathrm{Na}$ amostra oxidada, os teores mais elevados de Sn (superiores a $0,7 \%$ ) associam-se às frações inferiores a 0,21 mm, atingindo 1,08\% abaixo de 0,044 $\mathrm{mm}$. Em ambas as amostras o intervalo $-3,36+0,84 \mathrm{~mm}$ é responsável por cerca de 65 a $70 \%$ em massa e por $70 \%$ do total de estanho contido, correspondendo ainda a $47 \%$ do total de zinco para a sulfetada e a $51 \%$ para a oxidada. 
Tabela 2 - Distribuição de teores por fração granulométrica das amostras estudadas

\begin{tabular}{|c|c|c|c|c|c|c|c|c|c|c|}
\hline \multirow{3}{*}{ Fração (mm) } & \multicolumn{5}{|c|}{ AMOSTRA SULFETADA } & \multicolumn{5}{|c|}{ AMOSTRA OXIDADA } \\
\hline & \multirow{2}{*}{$\begin{array}{c}\% \\
\text { massa }\end{array}$} & \multicolumn{2}{|c|}{ Teores (\%) } & \multicolumn{2}{|c|}{ Distribuição (\%) } & \multirow{2}{*}{$\%$ massa } & \multicolumn{2}{|c|}{ Teores (\%) } & \multicolumn{2}{|c|}{ Distribuição (\%) } \\
\hline & & Sn & $\mathrm{Zn}$ & Sn & $Z n$ & & Sn & $\mathrm{Zn}$ & Sn & $\mathrm{Zn}$ \\
\hline$-3,36+2,80$ & 11,4 & 0,49 & 0,19 & 10,3 & 7,4 & 12,7 & 0,52 & 0,17 & 12,0 & 7,9 \\
\hline$-2,80+2,36$ & 20,2 & 0,56 & 0,19 & 20,7 & 12,9 & 20,0 & 0,63 & 0,17 & 22,8 & 12,0 \\
\hline$-2,36+1,68$ & 15,7 & 0,63 & 0,22 & 18,1 & 11,5 & 16,2 & 0,60 & 0,18 & 17,6 & 10,2 \\
\hline$-1,68+0,84$ & 17,4 & 0,62 & 0,25 & 19,6 & 14,9 & 20,6 & 0,47 & 0,29 & 17,6 & 21,1 \\
\hline$-0,84+0,42$ & 10,7 & 0,60 & 0,38 & 11,8 & 13,8 & 11,9 & 0,40 & 0,34 & 8,6 & 14,5 \\
\hline$-0,42+0,21$ & 8,7 & 0,44 & 0,46 & 7,0 & 13,7 & 8,9 & 0,46 & 0,46 & 7,5 & 14,7 \\
\hline$-0,21+0,074$ & 9,2 & 0,44 & 0,52 & 7,5 & 16,1 & 6,1 & 0,71 & 0,58 & 7,9 & 12,8 \\
\hline$-0,074+0,044$ & 2,5 & 0,38 & 0,44 & 1,8 & 3,8 & 1,7 & 0,81 & 0,53 & 2,5 & 3,3 \\
\hline$-0,044$ & 4,2 & 0,43 & 0,42 & 3,3 & 5,9 & 1,8 & 1,08 & 0,55 & 3,6 & 3,6 \\
\hline Total & 100,0 & 0,55 & 0,29 & 100,0 & 100,0 & 100,0 & 0,55 & 0,28 & 100,0 & 100,0 \\
\hline
\end{tabular}

\subsection{Composição mineralógica}

A composição mineralógica para o material acima de $0,074 \mathrm{~mm}$ de ambas as amostras é apresentada na tabela 3 .

Tabela 3 - Composição mineralógica das amostras estudadas (Total +0,074 mm; \% em massa) - MLA

\begin{tabular}{|c|c|ccccccccc|}
\hline AMOSTRA & \% em & \multicolumn{7}{|c|}{ Minerais (\% em massa) } \\
& massa & cassiterita & esfalerita & quartzo & mica & feldspato & caulinita & topázio & outros* \\
\hline SULFETADA & 93 & 0,5 & 0,4 & 39 & 27 & 6,2 & 13 & 11 & 3,6 \\
OXIDADA & 96 & 0,5 & 0,4 & 71 & 15 & 4,5 & 6,0 & 2,0 & 0,6 \\
\hline
\end{tabular}

*outros = estanita, fluorita, zircão, goethita, anatásio, calcita, dolomita, apatita, monazita, goiazita, calcopirita, wolframita, (AISrPS)CaF, sellaita, coulsellita e AICa(F-O).

As amostras são constituídas basicamente pela mesma assembleia mineralógica, composta por cassiterita, esfalerita, quartzo, mica, feldspato, caulinita, topázio e outros minerais (estanita, fluorita, zircão, goethita, anatásio, calcita, dolomita, apatita, monazita, goiazita, calcopirita, wolframita, (AISrPS)CaF, sellaita, coulsellita e AlCa(F-O), com variações significativas nas proporções relativas dos maiores constituintes. Comparativamente a amostra sulfetada é mais enriquecida em topázio ( $11 \%$ contra $2 \%)$, mica $(27 \%$ contra $15 \%)$, feldspato $(6,2 \%$ contra $4,5 \%)$, outros $(3,6 \%$ contra $0,6 \%$ ) e caulinita ( $13 \%$ contra $6,0 \%)$, enquanto que a amostra oxidada apresenta maior conteúdo de quartzo (71\% contra 39\%). Ambas as amostras têm a mesma proporção de cassiterita e esfalerita, com $0,5 \%$ e $0,4 \%$ em massa, respectivamente.

3.4 Partição dos elementos de interesse

As partições de Sn, Zn e S nos minerais portadores são apresentadas na tabela 4. 
A cassiterita responde praticamente pela totalidade do estanho presente em ambas as amostras; parcela da ordem de traços está associada à estanita (sulfeto de $\mathrm{Sn}, \mathrm{Cu}$ e Fe).

Na amostra sulfetada, a esfalerita é responsável pela totalidade do zinco contido e por $90 \%$ do enxofre (os $10 \%$ restantes estão associados a outros sulfetos). Já na oxidada, a esfalerita responde, também, pela totalidade do zinco contido e por $97 \%$ do enxofre (os 3\% restantes estão contidos em outros sulfetos).

Tabela 4 - Partição de Sn, Zn e S nos minerais portadores (total -3,36+0,074 mm)

\begin{tabular}{|l|ccc|ccc|}
\hline \multirow{2}{*}{ Mineral } & \multicolumn{3}{|c|}{ SULFETADA } & \multicolumn{3}{c|}{ OXIDADA } \\
& Sn & Zn & S & Sn & Zn & S \\
\hline Cassiterita & 100 & & & 100 & & \\
Estanita & $\operatorname{tr}$ & & & $\operatorname{tr}$ & & \\
Esfalerita & & 100 & 90 & & 100 & 97 \\
Outros sulfetos & & & 10 & & & 3 \\
\hline
\end{tabular}

\subsection{Características das associações minerais e liberação}

Na figura 1 são apresentadas imagens geradas nos estudos de MLA que ilustram as principais fases identificadas e formas de ocorrência da cassiterita e esfalerita.

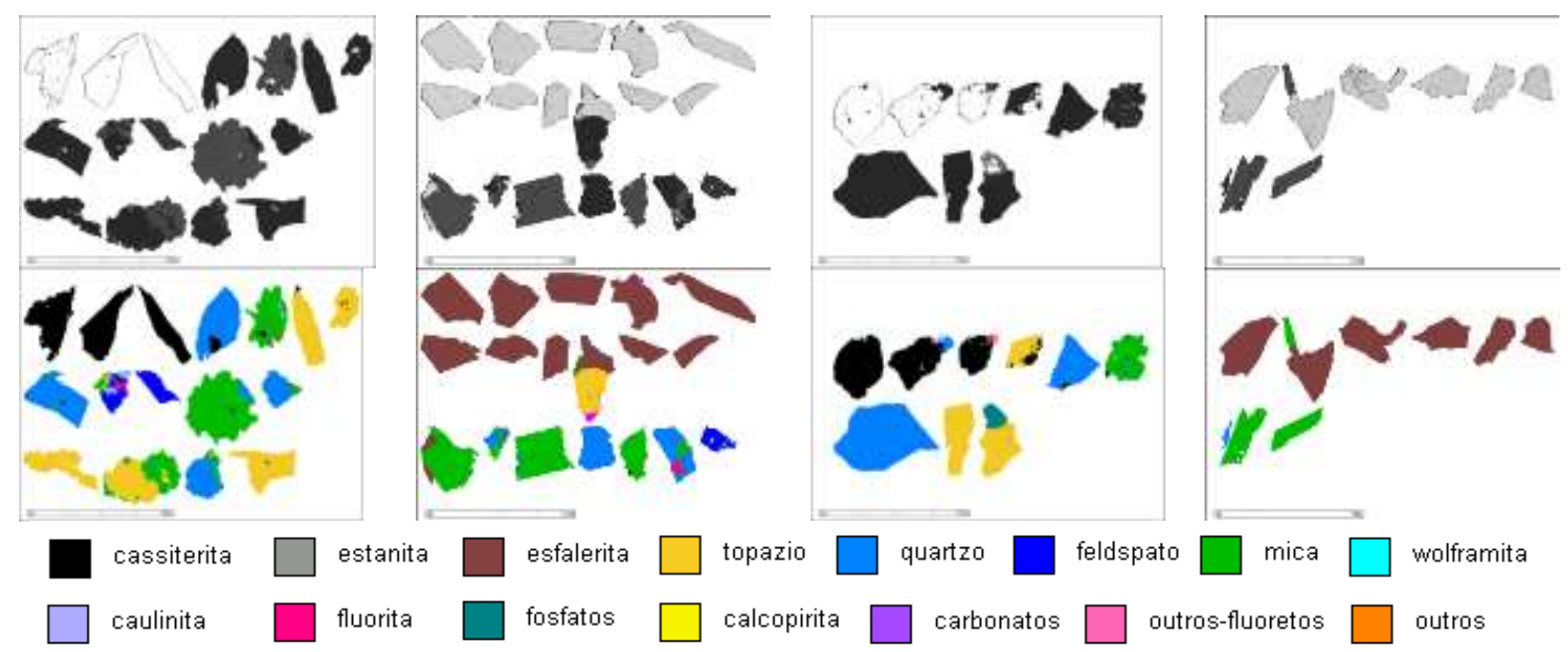

Figura 1 - Fotomicrografias das partículas extraídas das imagens de elétrons retroespalhados (BSE; acima) para classificação e processamento no MLA (em falsa cor). As partículas classificadas no MLA ilustram a distinção entre cassiterita e esfalerita e os principais minerais presentes

Em ambas as amostras, a cassiterita ocorre em grãos livres ou em partículas mistas com os silicatos (quartzo, feldspato, mica e topázio). A esfalerita na amostra sulfetada associa-se principalmente com mica, quartzo, topázio, feldspato e cassiterita, enquanto que na oxidada forma partículas mistas preferencialmente com mica e fluorita. 
As dimensões médias dos grãos de cassiterita são da ordem de 0,5 a 0,7 $\mathrm{mm}$ e a dos de esfalerita de 0,3 a $0,45 \mathrm{~mm}$.

As figuras 2 e 3 ilustram as curvas de espectro de liberação (considerando como livres as partículas constituídas por $95 \%$ ou mais em área de mineral de interesse) e formas de associação da cassiterita e esfalerita (\% em massa; entre mista e livre) por fração granulométrica.
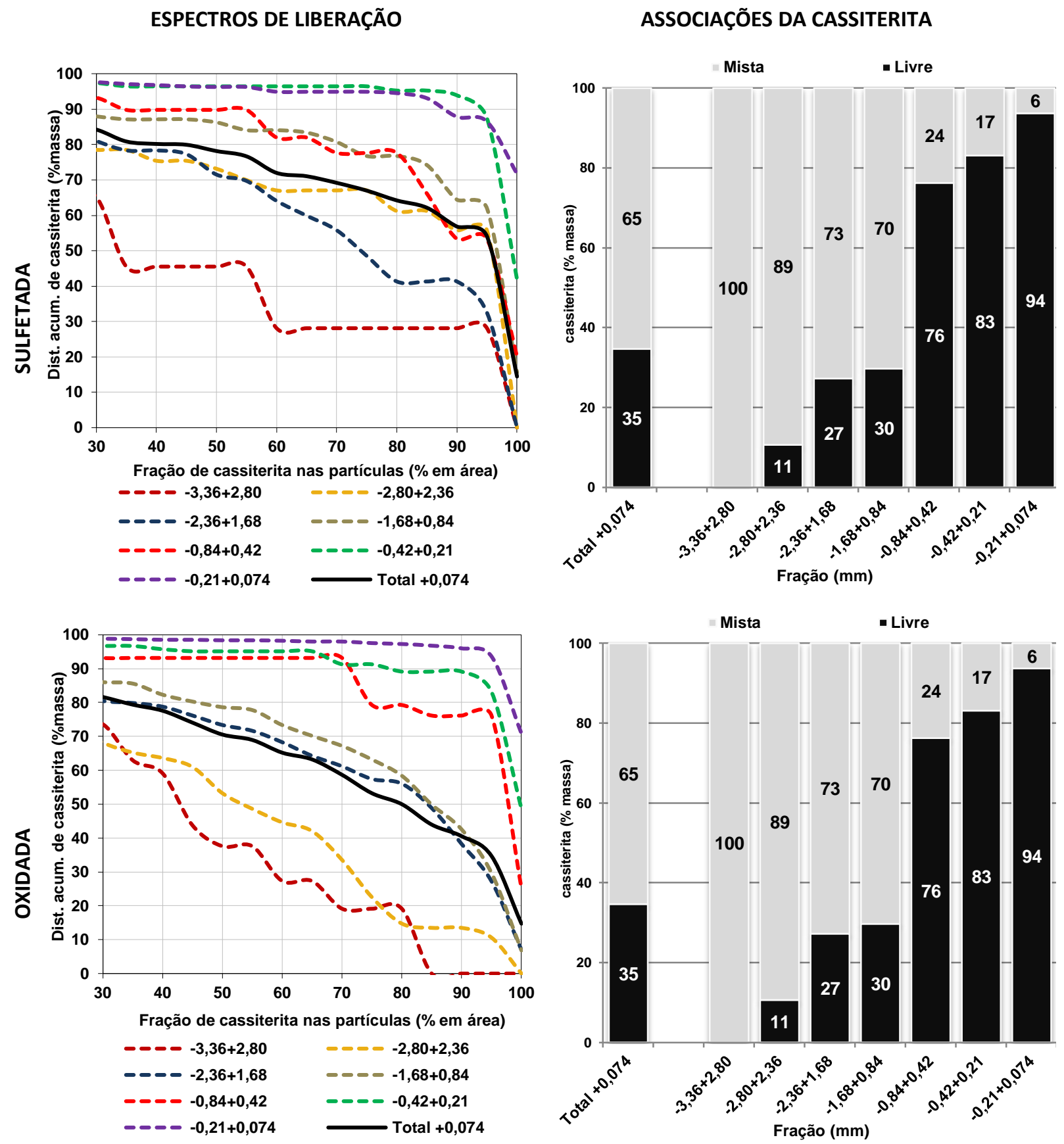

Figura 2 - Curvas de espectro de liberação (em área) e formas de associação da cassiterita 

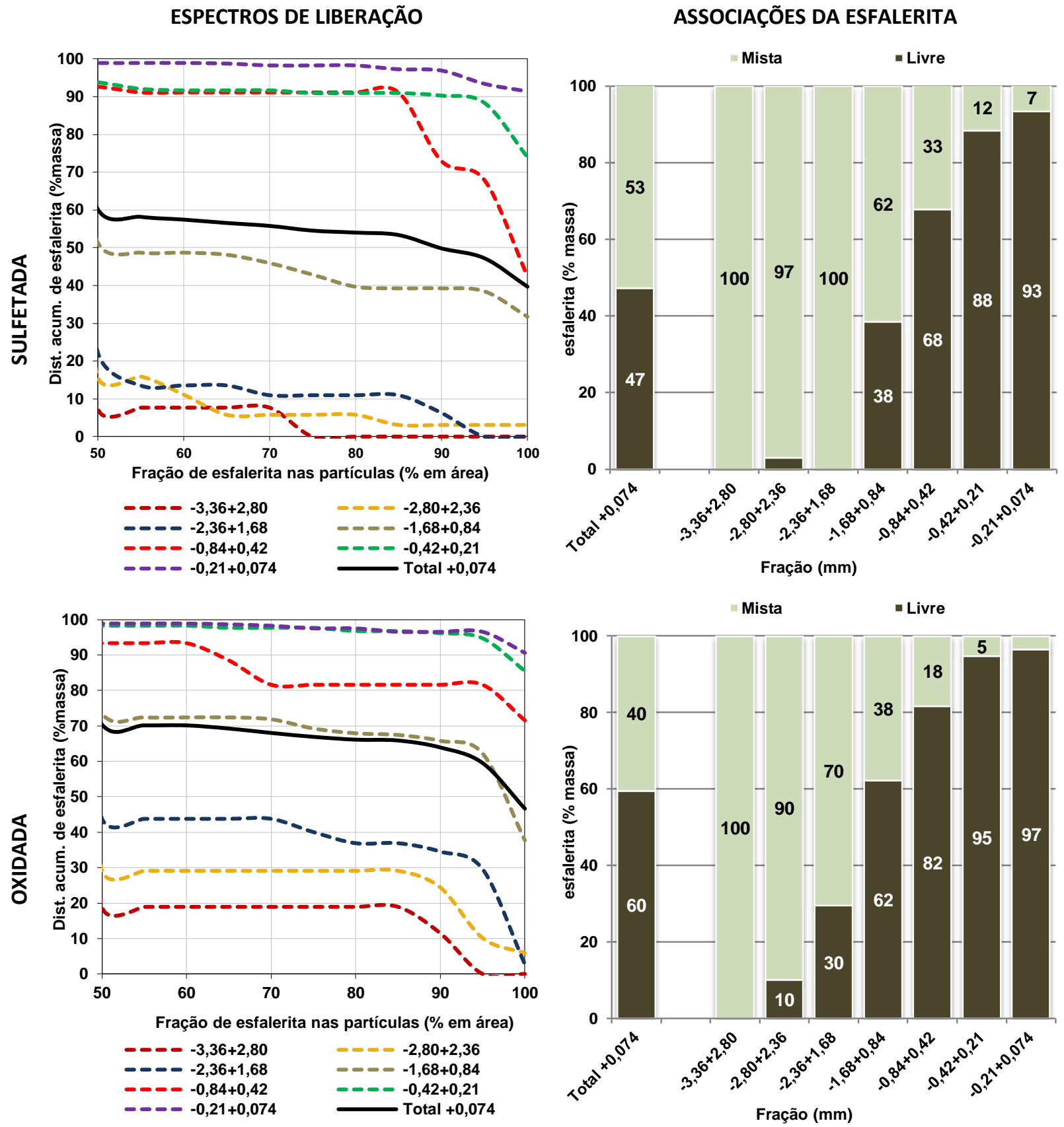

Figura 3 - Curvas de espectro de liberação (em área) e formas de associação da esfalerita

$\mathrm{Na}$ amostra sulfetada, a liberação da cassiterita corresponde a $54 \%$ em massa; acima de $0,42 \mathrm{~mm}$ sua liberação é baixa, situando-se entre $28 \%$ e $62 \%$, atingindo valores superiores a $85 \%$ abaixo dessa fração. Na amostra oxidada o grau de liberação da cassiterita é de 35\%; liberações superiores a $75 \%$ só são alcançadas abaixo de 0,84 mm, atingindo $94 \%$ abaixo de 0,21 mm. Acima de $2,80 \mathrm{~mm}$, praticamente não existem grãos liberados.

A esfalerita apresenta liberação global de $47 \%$ na amostra sulfetada e de $60 \%$ na oxidada. $\mathrm{Na}$ amostra sulfetada praticamente não ocorrem grãos livres de esfalerita até 1,68 mm, enquanto que na oxidada esta característica é observada até $2,80 \mathrm{~mm}$. Para a amostra sulfetada, liberação superior a $85 \%$ só são alcançadas abaixo de $0,42 \mathrm{~mm}$, enquanto que na oxidada esse valor é superior a $95 \%$ para o mesmo intervalo. 


\section{CONCLUSÕES}

As amostras estudadas (sulfetada e oxidada) apresentam teores semelhantes de estanho $(0,55 \%)$ e de zinco $(0,28-0,29 \%)$. As dimensões médias dos grãos de cassiterita são da ordem de 0,5 a $0,7 \mathrm{~mm}$ e a dos de esfalerita de 0,3 a $0,45 \mathrm{~mm}$.

Ambas as amostras apresentam assembleias mineralógicas muito semelhantes, variando a proporção relativa entre os principais minerais presentes: quartzo, feldspatos, mica e topázio; como minerais acessórios e traços são encontrados cassiterita, esfalerita, caulinita, dolomita, fluorita, apatita, monazita, goiazita, goethita, anatásio, calcita, estanita, calcopirita e wolframita, dentre outros.

O grau de liberação da cassiterita para o intervalo $-3,36+0,074 \mathrm{~mm}$ é de $54 \%$ na amostra sulfetada e de $35 \%$ para a amostra oxidada. Para processamento mineral, frente às características observadas para a cassiterita, a cominuição poderia ser efetuada em duas etapas, sendo uma mais grossa a partir da qual seria gerado um pré-concentrado a partir de estágios sucessivos de concentração gravítica (jigues, espirais) a ser cominuído na granulação de liberação da cassiterita e submetido a nova etapa de concentração (espirais e mesas oscilatórias); os mistos e rejeitos a depender dos teores de Sn e Zn seriam remoídos para a recuperação da esfalerita por flotação, obtendo-se ainda um eventual concentrado acabado de estanho (deprimido na flotação).

\section{REFERÊNCIAS BIBLIOGRÁFICAS}

1. FANDRICH, R.; GU, Y.; BURROWS, D.; MOELLER, K. Modern SEM-based mineral liberation analysis. International Journal of Mineral Processing, v. 84, p. 310-320, 2007.

2. KAHN, H.; GABAS, S. G.; ROSSI, F. G. N. Liberação de minérios por meio de análise de Imagens, IV Congresso Ítalo Brasileiro de Engenharia de Minas, Canela, RS. Revista Egatea, № especial, p.281 a 287, 1996.

3. KRAMER, R.; HWANG, J.Y.; Identification of low concentrate species in iron ore using SEM/EDS/image analysis. Process Mineralogy XII, ed. Petruk, W. et al. The Minerals, Metals and Materials Society, p. 309-317, 1994.

4. LASTRA, R; PETRUK, W.; Image analysis technique and applications to mineral processing. In: Modern Approaches to Ore and Environmental Mineralogy. Short Course by International Mineralogical Association / Laboratório do Instituto Geológico Mineiro. S. de Mamede de Infesta. Portugal, 1997.

5. PETRUK, W.; Short Course on Image Analysis Applied to Mineral and Earth Sciences. Mineralogical Association of Canada. p.156, 1989. 